\title{
A DIDÁTICA NA ATUALIDADE: UMA PESQUISA SOBRE OS ASSUNTOS ABORDADOS NO GT04 DA ANPED.
}

\author{
Daniele dos Santos Martins Vieira, Renata Portela Rinaldi \\ Universidade Estadual Paulista - UNESP, Faculdade de Ciências e Tecnologia, Curso de Licenciatura em Pedagogia, \\ Presidente Prudente, SP. E-mail: danielemartins1903@hotmail.com \\ Agência de fomento: $\mathrm{CNPq}$
}

\section{RESUMO}

A didática se configura como um campo amplo de investigação e possui como objeto de estudo o processo de ensino. Engloba várias ações sobre prática pedagógica, como também envolve a concepção de educação que o professor possui, pois à formação humana e integral é necessário considerar o cenário político, social, cultural e econômico em que os sujeitos estão inseridos. Diante do exposto, o objetivo deste artigo é analisar a partir das produções no campo, especificamente do Grupo de Trabalho de Didática (GT04) da Associação Nacional de PósGraduação e Pesquisa em Educação (ANPED), o que revelam sobre o papel da didática na formação de professores. Baseia-se na pesquisa qualitativa, do tipo bibliográfica; a coleta de dados ocorreu no banco de dados da ANPED, no período de2007-2017 e a análise dos dados foi realizada a partir de uma perspectiva descritivo-analítica. Os resultados revelam principalmente o enfoque das pesquisas na área investigada.

Palavras-chave: Didática, formação de professores, prática pedagógica, ANPED.

\section{THE DIDACTIC TODAY: A RESEARCH ON THE SUBJECTS ADDRESSED IN THE ANPED GT04.}

\begin{abstract}
The didactics is configured as a broad field of investigation and has as object of study the teaching process. It encompasses several actions on pedagogical practice, but also involves the conception of education that the teacher possesses, since to human and integral formation it is necessary to consider the political, social, cultural and economic scenario in which the subjects are inserted. In the light of the above, the objective of this article is to analyze from the productions in the field, specifically the Working Group on Didactics (GTO4) of the National Association of Postgraduate and Research in Education (ANPED), which reveal about the role of didactics in teacher training. It is based on the qualitative research, of the bibliographic type; the data collection took place in the ANPED database between 2007-2017 and data analysis was performed from a descriptiveanalytical perspective. The results reveal mainly the research focus in the researched area.
\end{abstract}

Keywords: Didactics, formation of teacher, pedagogical practice, ANPED. 


\title{
INTRODUÇÃO
}

A didática é compreendida como uma área de grande importância nos cursos de formação inicial de professores, pois ela orienta o profissional em todo o processo de ensino e aprendizagem, por exemplo, na definição de objetivos para o ensino, a seleção de conteúdos, a forma de organização da aula além de apoiar o planejamento de avaliações da aprendizagem. Todavia, o campo de pesquisa da Didática não fica restrito ao planejamento e a disciplina curricular nos cursos de formação de professores, ela engloba aspectos sociais, culturais, políticos e econômicos. Para Libâneo (2002):

\begin{abstract}
A atividade docente tem a ver diretamente com o "para quê educar", pois a educação se realiza numa sociedade formada por grupos sociais que têm uma visão distinta de finalidades educativas. Os grupos que detêm o poder político e econômico querem uma educação que forme pessoas submissas, que aceitem como natural a desigualdade social e o atuai sistema econômico. Os grupos que se identificam com as necessidades e aspirações do povo querem uma educação que contribua para formar crianças e jovens capazes de compreender criticamente as realidades sociais e de se colocarem como sujeitos ativos na tarefa de construção de uma sociedade mais humana e mais igualitária. (LIBÂNEO, 2002, p.5)
\end{abstract}

Dessa forma, o presente trabalho defende a didática como um campo que vai além de meras técnicas de transmissão de conteúdo. Concebendo o seu objeto de estudo, o ensino, numa perspectiva multidimensional (social, cultural política, de valores etc.), a compreendemos como uma área que viabiliza a formação integral de indivíduos para que compreendam seu papel na sociedade, que se tornem conhecedores de seus direitos e deveres, para que dessa forma, a equidade e a qualidade no campo da educação seja alcançada. Nesse sentido, concordamos com Libâneo (2002) quando conceitua:

A Didática, portanto, trata dos objetivos, condições e meios de realização do processo de ensino, ligando meios pedagógico-didáticos a objetivos sócio-políticos. Não há técnica pedagógica sem uma concepção de homem e de sociedade, como não há concepção de homem e sociedade sem uma competência técnica para realizá-la educacionalmente. (LIBÂNEO, 2002, P.5)

Dessa forma, buscaremos respostas às seguintes questões de pesquisa: Quais assuntos são tratados nas produções científicas sobre didática da ANPED? De que forma, nas produções, aparece o papel da didática na formação de professores? Para tanto, delineou-se como objetivo geral: analisar a partir das produções no campo, especificamente do GT04 da ANPED, o que revelam sobre o papel da didática na formação de professores.

\section{METODOLOGIA}

A pesquisa científica nos possibilita transitar por uma ampla área, frente às inúmeras possibilidades de investigação distintas por suas particularidades. Pensando em sua singularidade Ghedin e Franco (2011) apontam a natureza peculiar de cada investigação ao pensar no caráter da dialética, da intencionalidade, a localização no tempo e no espaço.

Ao nos remetermos às características e singularidades da pesquisa em tela, se estabelece que o enfoque mais apropriado é o qualitativo, pois possui rigor metodológico e possibilita novas descobertas ou ampliação das existentes, proporcionando novos delineamentos que não seriam possíveis na pesquisa puramente quantitativa. Percebemos, também, que a pesquisa qualitativa parte de questões amplas e no seu desenvolver apresenta delimitações frente aos dados que surgem em sua evolução. Assim, pautadas na abordagem qualitativa, com a preocupação em circunscrever o objeto investigado tendo em vista as características e as possibilidades oferecidas por esse tipo de pesquisa, realizamos a investigação por meio da pesquisa bibliográfica.

A pesquisa bibliográfica é desenvolvida a partir de material já elaborado, constituído principalmente de livros e artigos científicos. Segundo Gil (2012, p. 50), “[...] embora em quase 
todos os estudos seja exigido algum tipo de trabalho desta natureza, há pesquisas desenvolvidas exclusivamente a partir de fontes bibliográficas".

$\mathrm{Na}$ proposta em tela, a investigação ocorreu na base de dados digitais da Associação Nacional de Pós-Graduação e Pesquisa em Educação (ANPED), por sua grande contribuição e relevância no âmbito de pesquisas em educação. Especificamente, trabalhamos com as produções do Grupo de trabalho 04 de Didática (GT-04), no período de 2007 a $2017^{1}$. O recorte temporal se justifica, pela necessidade de conhecer como a área está sendo abordada na atualidade, além da associação dos dados aos três últimos governos do Brasil. Foram mapeados os artigos completos a partir dos descritores: formação Inicial e formação de professores e didática. A análise dos dados foi realizada a partir de uma perspectiva descritivo-analítica.

\section{RESULTADOS}

No decorrer da pesquisa, foi possível encontrar assuntos diversificados nos textos produzidos no grupo de trabalho pesquisado (GT-4) e após a constatação da repetição dos assuntos, foram criadas as categorias: Didática na formação de professores, formação de professores, formação inicial, práticas e metodologias de ensino, componente curricular, docência universitária. Verificamos, ainda, poucos artigos que versavam sobre assuntos diversificados no campo da didática e não se repetiam frequentemente entre as edições do evento, eles foram identificados como categoria outros.

Para melhor organização e análise dos dados, elaboramos o quadro $1^{2}$ em que é possível visualizar a quantidade de trabalhos e os assuntos abordados ao longo das edições do evento:

Quadro 1. Sistematização dos dados do GT04 por categoria.

\begin{tabular}{|c|c|c|c|c|c|c|c|c|c|c|}
\hline \multirow{3}{*}{ Categorias } & 2007 & 2008 & 2009 & 2010 & 2011 & 2012 & 2013 & 2015 & 2017 & \multirow{3}{*}{$\begin{array}{l}\text { Total } \\
\text { por } \\
\text { categoria }\end{array}$} \\
\hline & $\begin{array}{l}\text { T.T: } \\
16\end{array}$ & $\begin{array}{l}\text { T.T: } \\
18\end{array}$ & $\begin{array}{l}\text { T.T: } \\
12\end{array}$ & $\begin{array}{l}\text { T.T: } \\
13\end{array}$ & $\begin{array}{l}\text { T.T: } \\
13\end{array}$ & $\begin{array}{l}\text { T.T: } \\
21\end{array}$ & $\begin{array}{l}\text { T.T: } \\
09\end{array}$ & $\begin{array}{l}\text { T.T: } \\
15\end{array}$ & $\begin{array}{l}\text { T.T: } \\
14\end{array}$ & \\
\hline & $\begin{array}{l}\text { T.S: } \\
00\end{array}$ & $\begin{array}{l}\text { T.S: } \\
01\end{array}$ & $\begin{array}{l}\text { T.S: } \\
01\end{array}$ & $\begin{array}{l}\text { T.S: } \\
00\end{array}$ & $\begin{array}{l}\text { T.S: } \\
00\end{array}$ & $\begin{array}{l}\text { T.S: } \\
04\end{array}$ & $\begin{array}{l}\text { T.S: } \\
01\end{array}$ & $\begin{array}{l}\text { T.S: } \\
00\end{array}$ & $\begin{array}{l}\text { T.S: } \\
04\end{array}$ & \\
\hline $\begin{array}{c}\text { O papel da } \\
\text { Didática na formação de } \\
\text { professores }\end{array}$ & 00 & 01 & 01 & 00 & 00 & 04 & 01 & 00 & 04 & 11 \\
\hline Formação de professores & 00 & 03 & 01 & 02 & 01 & 02 & 02 & 00 & 00 & 12 \\
\hline Formação Inicial & 01 & 00 & 00 & 00 & 01 & 00 & 01 & 01 & 00 & 04 \\
\hline $\begin{array}{l}\text { Práticas e metodologias de } \\
\text { ensino }\end{array}$ & 05 & 05 & 03 & 04 & 08 & 03 & 00 & 11 & 07 & 46 \\
\hline Didática específica & 01 & 03 & 00 & 03 & 01 & 07 & 00 & 01 & 00 & 16 \\
\hline Docência universitária & 02 & 01 & 01 & 02 & 01 & 02 & 03 & 02 & 02 & 16 \\
\hline Outros. & 07 & 05 & 06 & 02 & 01 & 03 & 02 & 00 & 01 & 27 \\
\hline $\begin{array}{c}\text { Total de todos os trabalhos } \\
\text { analisados }\end{array}$ & \multicolumn{10}{|l|}{131} \\
\hline $\begin{array}{c}\text { Total de todos os trabalhos } \\
\text { selecionados }\end{array}$ & \multicolumn{10}{|l|}{11} \\
\hline
\end{tabular}

Fonte: Dados organizados pelas autoras, a partir do levantamento bibliográfico na base de dados da ANPED em 2018.

Para melhor visualização dos resultados, no gráfico 1 é possível percebera recorrência (ou não) dos assuntos nas diversas edições das Reuniões Nacionais ANPED:

\footnotetext{
${ }^{1}$ As reuniões do evento inicialmente ocorriam anualmente, mas a partir do ano de 2013 passaram a ser bianuais, portanto, a pesquisa compreende os anos de: 2007, 2008, 2009, 2010, 2011, 2012, 2013, 2015 e 2017.

${ }^{2}$ As abreviações, "T.T", que representa o total de trabalhos apresentados no ano; "T.S" indica os trabalhos que foram selecionados na edição do evento a partir dos critérios previamente definidos.
} 
Gráfico 1. Assuntos encontrados nas publicações do Gt 04 da ANPED

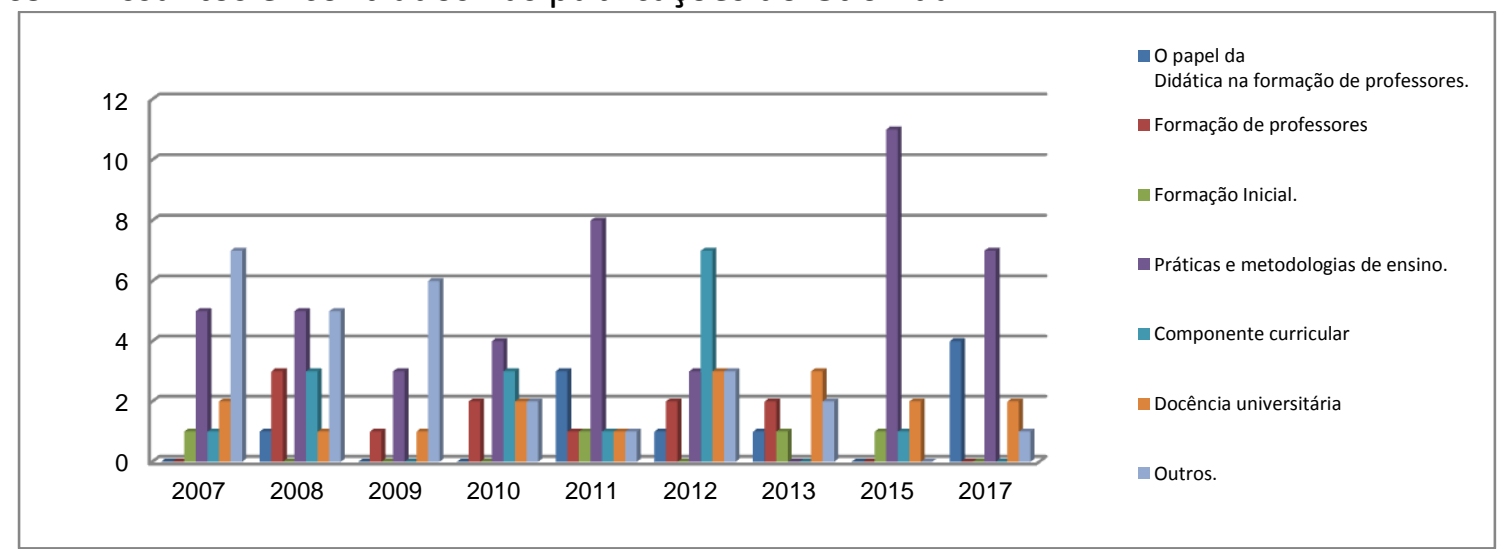

Fonte: Gráfico organizado pelas autoras a partir dos resultados obtidos.

O gráfico acima evidencia uma regularidade nas produções que discutem práticas e metodologias de ensino, da mesma forma, a docência universitária também comparece como temática investigada em todas as reuniões, ainda que com baixa frequência. A categoria "o papel da didática na formação de professores" comparece em todas as reuniões, com oscilação no interesse dos pesquisadores ao longo dos anos.

O gráfico2 apresenta os trabalhos identificados na base de dados e aqueles que foram selecionados para compor o corpus de análise da pesquisa. É possível observar a discrepância que se apresenta ao selecionar somente os artigos que tratavam da didática especificamente na formação de professor.

Gráfico 2. Comparativo do total de trabalhos análisados e selecionados nas edições da última década da ANPED

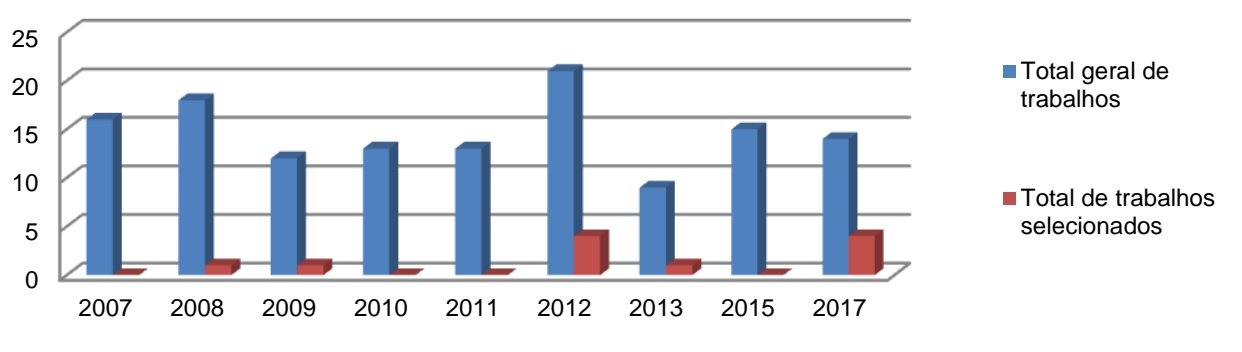

Fonte: Gráfico organizado pelas autoras a partir dos resultados obtidos.

Diante das análises dos textos constatou-se a amplitude da abordagem da área de didática nas produções cientificas, pois dentro de um único grupo de trabalhos, foi possível encontrar diversos elementos que compõem o campo investigado, nem sempre com foco na formação de professores.

\section{DISCUSSÕES}

Diante dos dados obtidos foi possível chegar aos resultados sobre os assuntos que vem se repercutindo nas produções sobre didática nas publicações da ANPED, no GT-04, sendo identificados 131 artigos no total, mas apenas 11 selecionados para análise a partir dos critérios estabelecidos na pesquisa.

Observamos um padrão na quantidade de trabalhos produzidos anos de 2007, 2008, 2009, 2010 e 2011, o que não ocorreu no ano de 2012, a qual houve uma grande alta de textos 
produzidos nessa edição e em 2013 aconteceu à maior queda no número de trabalhos do GT04 e nos anos seguintes esses números de produções se restabeleceram.

Observamos que a categoria de práticas e metodologias de ensino ganhou destaque pelo número de produções dentro do GT-04, apresentando o maior número de textos produzidos sobre o assunto, já no caso da formação inicial foi outro campo que chamou a atenção, pois essa área se tornou a menos investigada ao longo do tempo. Provavelmente essa questão pode ter ocorrido porque os autores dos artigos tenham submetido suas produções no GT específico sobre formação de professores, essa seria uma das respostas considerada analogicamente.

No presente texto foi destacada como trabalhos selecionados a questão do papel da didática na formação de professores, esse assunto ganhou relevância durante as análises realizadas por acreditar que área investigada possui um papel matriarcal nas licenciaturas, pois o campo investigado possui como objeto de estudo o ensino, que permite o acesso a todas as práticas pedagógicas. Nessa direção, Libâneo (2013) nos esclarece o papel que a didática possui no contexto educacional:

[...] a didática uma disciplina que estuda os objetivos, os conteúdos, os meios e as condições do processo de ensino tendo em vista finalidades educacionais, que são sempre sociais, ela se fundamenta na pedagogia; é assim, uma disciplina pedagógica. (LIBÂNEO, 2013, p. 13-14).

Por esse motivo, existe a preocupação nas pesquisas que vêm sendo produzidas sobre didática, pois quando deixamos de nos preocupar sobre o papel que ela possui na formação de professores, perdemos espaço da área nas produções científicas, nos cursos de licenciaturas. Diante dos resultados, surgem novas inquietações que ampliarão a pesquisa, em desenvolvimento: Como falar de tantos assuntos sobre didática deixando de lado o papel que é atribuído a ela nos cursos de formação de professores? É importante lembrar, sem a formação didática adequada, como vamos apresentar trabalhos no campo de práticas e metodologias ou qualquer outro assunto que advém da prática pedagógica?

Portanto, vale ressaltar sobre a importância do espaço da didática nos cursos de formação de professores, considerando-a como uma disciplina matricial que considere as questões políticas, sociais, culturais, econômicas e acima de tudo que promova possibilidades significativas para uma formação integral do indivíduo.

\section{CONCLUSÃO}

Foi possível compreender, diante dos resultados obtidos, o que revelam as pesquisas sobre a didática e visualizar o contexto de produções cientificas do campo investigado na última década nos trabalhos publicados no GT-04, nas edições das Reuniões Anuais da ANPED. Além de identificar os assuntos tratados no grupo de trabalhos na atualidade, também foi possível identificar quantos artigos vislumbraram o papel da didática na formação de professores e esse, se revela um dado preocupante. Pois, ao considerarmos a importância da temática, estamos garantindo o espaço da didática nas pesquisas científicas e contribuindo para a solidificação da área nos cursos de licenciaturas, pois através da compreensão do papel que é atribuído a ela, será possível constatar qual a prática docente está sendo privilegiada. Assim, o entendimento sobre o campo investigado interfere nas ações pedagógicas e, consequentemente, no processo de ensino e aprendizagem.

Com o exposto, conclui-se que a forma em que a didática é compreendida influenciará a atuação docente, frente a essa situação, devemos levar em consideração qual concepção de educação possuo e quais cidadãos serão formados para atuarem como seres emancipados e participativos em nosso país. 


\section{REFERÊNCIAS}

FRANCO. M. L.P.B. Análise de conteúdo. 3ed. Brasília: Liber livro editora, 2008.

GHEDIN, E.; FRANCO, M. A. S. Questões de método na construção da pesquisa em educação. 2 ed. São Paulo: Cortez, 2011.

GIL, A. C. (Org.). Métodos e técnicas de pesquisa social. 6ạ. Ed. São Paulo: Atlas, 2012.

LIBÂNEO. J. C. DIDÁTICA Velhos e novos temas. Goiânia: Edição do Autor, 2002.

LIBÂNEO. J. C. Didática. 2.ed. São Paulo: Cortez, 2013.

TRIVIÑOS, A. N. S. Introdução à Pesquisa em Ciências Sociais: e pesquisa qualitativa em educação. São Paulo: Atlas, 2009. Reimpressão 